\title{
Chronic anemia in adult patients with cardiovascular diseases, diagnosed clinically and by trans-thoracic-2-dimensional echocardiography: a semi-urban tertiary care teaching hospital study
}

\author{
Rajendra Kumar Jatav ${ }^{1 *}$, Mamta B. Kumbhare ${ }^{2}$, Chalmeda Niveditha ${ }^{3}$
}

\author{
${ }^{1}$ Associate Professor, ${ }^{3}$ P.G. Student, Department of Medicine, Chalmeda Anand Rao Institute of Medical Sciences \\ (CAIMS), Bommakal, Karimnagar-505001, Telangana, India \\ ${ }^{2}$ Senior Specialist, Department of Anesthesia, Dhanvanthari Hospital, NTPC, RSTPS, Jyothinagar, Karimnagar- \\ 505215, Telangana, India
}

Received: 8 July 2014

Accepted: 19 July 2014

\section{*Correspondence:}

Dr. Rajendra Kumar Jatav,

E-mail: krajendramamta@gmail.com

Copyright: ( $)$ the author(s), publisher and licensee Medip Academy. This is an open-access article distributed under the terms of the Creative Commons Attribution Non-Commercial License, which permits unrestricted non-commercial use, distribution, and reproduction in any medium, provided the original work is properly cited.

\begin{abstract}
Background: Anemia is one of the major health challenges to global development in this century and this NonCommunicable Disease is rapidly rising in both developed and developing countries. Chronic anemia is a risk factor for cardiovascular diseases and affect outcome in patients with heart failure, dilated cardiomyopathy and uncontrolled hypertension. Chronic anemia's have significant morbidity and mortality in untreated patients. This study was performed to analyze the prevalence of anemia among cardiac patients and to determine the relationship between anemia and socio demographic characteristics.

Methods: We enrolled 300 adults' cardiac patients $(\geq 19$ years) during study period. The analysis includes socio demographic data, traditional risk factors for cardiovascular diseases, laboratory test (hemoglobin and creatinine clearance measurement), and non-invasive cardiac investigations.

Results: Our analysis suggests prevalence of anemia is very high in CVSD patients \& more common among females, older age, diabetics, impaired clearance creatinine, hypertensive and low education level. The highest proportion belonged to valvular heart disease (77.8\%), congestive heart failure (74.6\%) followed by hypertension (54\%), and the lowest is coronary artery disease (46\%). Logistic regression reveals that low education, low clearance creatinine level, smoking and diabetes are independently associated with anemia.

Conclusion: We conclude that anemia is common among cardiovascular disease patients, and worsens the prognosis of their clinical condition. Intervention policies to minimize anemia risk factors are needed.
\end{abstract}

Keywords: Anemia, Cardiovascular diseases, Socio demographic factors, Trans-thoracic-two-dimensional echocardiography

\section{INTRODUCTION}

According to WHO anemia is the qualitative and /or quantitative diminution of hemoglobin or RBC or both in respect to the age and sex of the individual and as per Robbins $^{1}$ anemia is defined as a reduction of the total circulating red cell mass below normal limits. Anemia is a one of the major health challenges to global development in this century and it is rapidly raising noncommunicable diseases in both developed and developing countries. This growing challenge threatens economic and social development as well as the lives and health of millions of people. The Eastern Mediterranean region is facing a growing epidemic of CVDs provoked by ageing population and socioeconomic changes. CVD risk factors were obesity (61.5\%), hypercholesterolemia (37.8\%), 
hypertension (30.7\%), diabetes (46.7\%), physical inactivity (46.8\%) and smoking $16.3 \% .^{2}$

In westernized countries, CVD accounts for the majority of deaths each year. It is reported that anemia may present a special risk in these patients. ${ }^{3}$ Considering high prevalence of anemia in general population and direct impact on patient's health, anemia causes important physiologic effects on the cardiovascular system; however studies measuring anemia prevalence in population are rare. CVDs, are the most common cause of death worldwide, including $(40 \%)$ in high-income countries, and $(28 \%)$ in low and middle-income countries. ${ }^{4}$ Mark et al. explained that anemia, is an independent risk factor for CVD outcomes in the ARIC cohort, a community cohort of subjects between the ages of 45 and 64 years. ${ }^{5}$ Paulo suggest that mild anemia was independent modifiable risk factor, for older adults and it was synergistically modified by the presence of CVD. ${ }^{6}$

Anemia is a major problem in India especially in pregnant women but young adult women between the ages 15 to 25 who are non-pregnant are also especially vulnerable to anemia. Though anemia is less common among males but they may also suffer from anemia in a considerable extent to their counterparts in developed and developing countries. Adverse effects of anemia are various as for example on nervous system, on physical response to diseases, physiological stressed condition like pregnancies. Iron, vitamin $\mathrm{B}_{12}$ and folate deficiencies are the common causes of anemia. Anemia is wide spread in India but it varies in severity from state to state and zone to zone. Poor diet, lack of sense of hygiene which leads to worm infestations, lack of health consciousness social taboos and poor economic status all contributes to overwhelming prevalence of anemia. Majority of the anemia can be treated in primary or secondary health care systems. Even primordial prevention can arrest a sizable number of anemia before development. Despite of different programs taken by the government for primary and primordial prevention of anemia among vulnerable groups the prevalence is on the rise. So we want to focus on the prevalence so that newer innovative and effective methods can be taken against this growing menace.

\section{METHODS}

This was a prospective, single center, longitudinal study conducted by the department of medicine at Chalmeda Anand Rao institute of medical sciences, a semi-urban tertiary care teaching hospital, Bommakal village, Karimnagar district, Telangana, India, over a period of three year from May 2011 to May 2014. The aim of the present study was to analyze the prevalence of anemia in adult patients with cardiovascular disease and explore main associated health morbidity and the socio demographic factors.

We included 300 adults patients (age $\geq 19$ years), who were hospitalized, attending OPD and coming for follow up in department of medicine, during study period of three years. The patients were evaluated regarding their demographic data, cardiovascular risk factors, main clinical diagnosis and laboratory data.

Laboratory test included hemoglobin and clearance creatinine level. In our study the definition of anemia is, if the Hemoglobin level is less than $13 \mathrm{~g} / \mathrm{dl}$ for men and $12 \mathrm{~g} / \mathrm{dl}$ for women (non-pregnant) based on World Health Organization. Anemic patients were classified into following groups: severely anemic ( $\mathrm{Hb}<7$ gm/l), moderate to mild anemic ( $\mathrm{Hb} 7-10 \mathrm{gm} \%$ ), mild anemic to low normal (Hb 10-13 gm/l), absolutely normal ( $\mathrm{Hb}>13$ $15 \mathrm{gm} / \mathrm{l})$ and healthy patients $(\mathrm{Hb}>15 \mathrm{gm} / \mathrm{l})$. Chronic kidney disease is defined by calculation of creatinine clearance according to Cockcroft-Gault equation (140age) $\times$ weight $(\mathrm{kg}) \times(0.85$ for female or 1 for male $) / 72 \times$ serum creatinine $(\mathrm{mg} / \mathrm{dl})$. If creatinine clearance is less than $85 \mathrm{ml} / \mathrm{min}$ means impaired renal function and equal or more than $85 \mathrm{ml} / \mathrm{min}$ means renal function is normal. In the present study, CVDs were diagnosed by noninvasive cardiac investigations included: ECG, X-ray Chest \& TTE. The TTE studies were performed using two commercially available cardiac ultrasound systems (ESAOTE - Megas-GPX and Phillips Clear Vue 550) with 2.5 to $4 \mathrm{MHz}$ phased array imaging transducers. Both systems were capable of M-Mode, color flow Doppler and spectral Doppler echocardiography. All patients underwent standard TTE views including Parasternal Long Axis (PLAX), Parasternal Short Axis (PSAX), Parasternal High Short Axis view (PHSX), supra sternal view, apical 2, 3, 4 and 5 chamber views as well as subcostal four chamber and short axis views. The studies were performed with the patient in supine and left lateral decubitus positions during quiet respiration. All the studies were taped, and hard copies were taken for further analysis, measurements \& reviewed by all authors. Socio demographic variables were patient's age, gender, level of education, citizenship (citizen or refugee), family size and place of residence (city, camp). In addition, traditional cardiovascular risk factors were determined, hypertension, diabetes, cigarette smoking, body mass index ( $\geq 30 \mathrm{~kg} / \mathrm{m}^{2}$ is obese). Collected data was analyzed by using statistical package for social science version 20.0; numbers and percentage were used to describe the baseline characteristics. In this study, relative frequency of anemia in various CVDs and different age group was assessed. Chi square test was used to examine the statistical significance differences between groups. The odds ratio and confidence interval of each risk factor was calculated. The differences between means were tested by t-test. In the end, logistic analysis was used to reveal the predictors that can be associated independently with anemia. The $\mathrm{P}$ value less than 0.05 were considered statistically significant.

\section{RESULTS}

Out of 300 cardiac patients, 181 patients $(60.3 \%)$ were anemic and $119(39.7 \%)$ were non-anemic. Table 1 
shows the characteristics of study population by anemia status. Among the patients, there were 153 (51\%) men vs. $147(49 \%)$ women. The prevalence of anemia among female patients $105(71.4 \%)$ is higher than male patients $76(49.7 \%)$. The difference between the two groups reached statistical significant level ( $\mathrm{P}$ value $<0.001$ ). The mean age for all study population was 61.4 years. Mean age in anemic patients tends to be higher (63.9 years) than non-anemic (57.7 years) and the difference between the two means reached statistical significant level ( $P$ value $<0.001)$. Analysis of age group showed that the prevalence of anemia increased by the age, increase which is progressive and statically significant. The higher rate of anemia prevalence in our population belongs to the age group older than 70 years $(71.1 \%)$, the difference between age groups is statistically significant $(\mathrm{P}$ value $<0.001$ ). Our findings revealed a relationship between education level and anemia. The prevalence of anemia among low educated patients is two times higher than the patients with high education level $(64.5 \%$ vs. $35.5 \%)$ and the difference reached statistical significant level ( $\mathrm{P}$ value $<0.001)$. A minor difference that did not reach statistical significant level is observed between patients classified by citizenship, residency and family size.

Table 1: Socio demographic characteristic of CVSDs patients in the present study stratified, by presence or absence of anemia.

\begin{tabular}{|c|c|c|c|c|c|c|c|}
\hline \multirow{3}{*}{$\begin{array}{l}\text { Demographic } \\
\text { characteristics }\end{array}$} & \multicolumn{2}{|c|}{$\begin{array}{l}\text { Anemia } \\
\text { present }\end{array}$} & \multicolumn{2}{|c|}{$\begin{array}{l}\text { Anemia } \\
\text { absent }\end{array}$} & \multicolumn{2}{|c|}{ Total } & \multirow{3}{*}{ OR $(95 \% \mathrm{CI})$} \\
\hline & No. & $\%$ & No. & $\%$ & No. & $\%$ & \\
\hline & 181 & 60.33 & 119 & 39.66 & 300 & 100 & \\
\hline \multicolumn{8}{|l|}{ Gender } \\
\hline Male & 76 & 49.67 & 77 & 50.32 & 153 & 51 & \multirow{2}{*}{$0.39(0.3-0.6)$} \\
\hline Female & 105 & 71.42 & 42 & 28.57 & 147 & 49 & \\
\hline \multicolumn{8}{|l|}{ Age } \\
\hline Mean & 63.9 & & 57.7 & & 61.4 & & \\
\hline$<55$ years & 35 & 41.17 & 50 & 58.82 & 85 & 28.33 & \multirow{3}{*}{$\begin{array}{l}1 \\
2.76(1.5-5.0) \\
3.50(1.8-7.0)\end{array}$} \\
\hline 56-69 years & 87 & 65.90 & 45 & 34.09 & 132 & 44 & \\
\hline$>70$ years & 59 & 71.08 & 24 & 28.91 & 83 & 27.66 & \\
\hline \multicolumn{8}{|l|}{ Education } \\
\hline Low & 169 & 64.50 & 93 & 35.49 & 262 & 87.33 & \multirow{2}{*}{$3.9(1.9-8.2)$} \\
\hline High & 12 & 31.57 & 26 & 68.42 & 38 & 12.66 & \\
\hline \multicolumn{8}{|l|}{ Citizenship } \\
\hline Citizen & 115 & 61.82 & 71 & 38.17 & 186 & 62 & \multirow{2}{*}{$0.80(0.5-1.4)$} \\
\hline Refugee & 66 & 57.89 & 48 & 42.10 & 114 & 38 & \\
\hline \multicolumn{8}{|l|}{ Residence } \\
\hline City & 110 & 59.78 & 74 & 40.21 & 184 & 61.33 & \multirow{2}{*}{$1.0(0.66-1.7)$} \\
\hline Camp & 71 & 61.20 & 45 & 38.79 & 116 & 38.66 & \\
\hline \multicolumn{8}{|l|}{ Family size } \\
\hline $0-8$ & 100 & 60.60 & 65 & 39.39 & 165 & 55 & \multirow{2}{*}{$1.0(0.6-1.6)$} \\
\hline$>8$ & 81 & 60 & 54 & 40 & 135 & 45 & \\
\hline
\end{tabular}

CI: Confidence intervals, OR: Operator, No.: Number

Table 2: Prevalence of anemia in different types of CVSDs included in the present study and diagnosed clinically and by TTE.

\begin{tabular}{|llllllll|}
\hline \multirow{2}{*}{ CVSDs } & \multicolumn{2}{l}{ CVSDs } & \multicolumn{2}{l}{$\begin{array}{l}\text { Anemia } \\
\text { present }\end{array}$} & \multicolumn{2}{l|}{$\begin{array}{l}\text { Anemia } \\
\text { absent }\end{array}$} & P \\
& No. & \% & No. & \% & No. & \% & value \\
\hline VHD & 07 & 77.77 & 02 & 22.22 & 09 & 3 & 0.001 \\
\hline CHF & 94 & 74.60 & 32 & 25.39 & 126 & 42 & 0.001 \\
\hline HTN & 27 & 54 & 23 & 46 & 50 & 16.66 & 0.001 \\
\hline CAD & 53 & 46.08 & 62 & 53.91 & 115 & 38.33 & 0.001 \\
\hline
\end{tabular}

The cardiovascular diseases included in our study are: Valvular Heart Disease (VHD), Congestive Heart Failure (CHF), hypertension (HTN) and Coronary Artery Disease (CAD) were shown in Table 2. According to our findings the highest prevalence of anemia is reported in VHD, patients with $\mathrm{CHF}$ are at the second place, followed by patients with $\mathrm{HTN}$, while patients with CAD reported the lowest prevalence rate.

Table 3 shows that anemia is more prevalent among hypertensive patients (65\% vs. $47.5 \%)$ and the difference between hypertensive and normotensive is statistically 
significant ( $\mathrm{P}$ value $<0.006)$. The same difference was observed among diabetics $(70 \%)$ than non-diabetics (49.3\%). Chance of anemia is less among smokers (38\%) than among non-smokers $(67.2 \%)$ with statistical significant difference ( $\mathrm{P}$ value $<0.001)$. Our findings also demonstrate that chances of anemia are 3.5 folds higher among patients with impaired creatinine clearance $(\mathrm{P}$ value $<0.001)$. Anemic patients have larger body mass index (31.4 vs. 30.1), this difference was statistically significant ( $\mathrm{P}$ value 0.035 ).

Table 3: Clinical and laboratory characteristics of CVSDS patients in our study stratified, by presence or absence of anemia.

\begin{tabular}{|c|c|c|c|c|c|c|c|c|}
\hline \multirow{2}{*}{$\begin{array}{l}\text { Characteristics } \\
\text { of patients in } \\
\text { present study }\end{array}$} & \multicolumn{2}{|c|}{$\begin{array}{l}\text { Anemia } \\
\text { present }\end{array}$} & \multicolumn{2}{|c|}{$\begin{array}{l}\text { Anemia } \\
\text { absent }\end{array}$} & \multicolumn{2}{|c|}{ Total } & \multirow{2}{*}{ OR $(95 \% \mathrm{CI})$} & \multirow{2}{*}{$\begin{array}{l}P \\
\text { value }\end{array}$} \\
\hline & No. & $\%$ & No. & $\%$ & No. & $\%$ & & \\
\hline \multicolumn{9}{|l|}{ Hypertension } \\
\hline Yes & 143 & 65 & 77 & 35 & 220 & 73.33 & \multirow{2}{*}{$2(1.2-3.4)$} & \multirow{2}{*}{0.006} \\
\hline No & 38 & 47.5 & 42 & 52.5 & 80 & 26.66 & & \\
\hline \multicolumn{9}{|l|}{ Diabetes } \\
\hline Yes & 112 & 70 & 48 & 30 & 160 & 53.33 & \multirow{2}{*}{$2.4(1.5-3.9)$} & \multirow{2}{*}{0.001} \\
\hline No & 69 & 49.28 & 71 & 50.71 & 140 & 46.7 & & \\
\hline \multicolumn{9}{|l|}{ Smoking } \\
\hline Yes & 27 & 38.02 & 44 & 61.97 & 71 & 23.66 & \multirow{2}{*}{$0.2(0.2-0.5)$} & \multirow{2}{*}{0.001} \\
\hline No & 154 & 67.24 & 75 & 32.75 & 229 & 76.33 & & \\
\hline \multicolumn{9}{|c|}{ Creatinine clearance } \\
\hline $\begin{array}{l}\text { Normal } \\
(<85 \mathrm{ml} / \mathrm{min})\end{array}$ & 39 & 40.20 & 58 & 59.79 & 97 & 32.33 & \multirow{2}{*}{$3.5(2.0-5.7)$} & \multirow{2}{*}{0.000} \\
\hline $\begin{array}{l}\text { Impaired } \\
(>85 \mathrm{ml} / \mathrm{min})\end{array}$ & 142 & 69.95 & 61 & 30.04 & 203 & 67.66 & & \\
\hline $\begin{array}{l}\text { Mean body } \\
\text { mass index }\end{array}$ & \multicolumn{2}{|l|}{31.4} & \multicolumn{2}{|l|}{30.1} & \multicolumn{2}{|c|}{30.9} & & 0.035 \\
\hline Mean $\mathrm{Hb}$ & \multicolumn{2}{|l|}{10.9} & \multicolumn{2}{|l|}{13.8} & \multicolumn{2}{|c|}{12.1} & & 0.001 \\
\hline $\begin{array}{l}\text { Mean clearance } \\
\text { creatinine }\end{array}$ & \multicolumn{2}{|l|}{65.4} & \multicolumn{2}{|l|}{92.6} & \multicolumn{2}{|c|}{76.6} & & 0,001 \\
\hline
\end{tabular}

To control for the confounding effects of the different risk factors we constructed multivariate analysis by the use of the logistic regression analysis. The dependent variable is anemia status and the covariates included clearance creatinine level, smoking, low education, diabetes mellitus, hypertension, body mass index and age as demonstrated in Table 4. The significant predictors that can affect anemia independently are clearance creatinine level, smoking, low education and diabetes mellitus.

Table 4: Logistic regression for the risk factors for anemia.

\begin{tabular}{|lllll|}
\hline & B. & S.E. & Sig. & $\begin{array}{l}\text { OR } \\
(95 \% \text { CI })\end{array}$ \\
\hline $\begin{array}{l}\text { Creatinine } \\
\text { clearance }\end{array}$ & 0.99 & 0.29 & 0.007 & $\begin{array}{l}2.69 \\
(1.51-4.79)\end{array}$ \\
\hline Smoking & 0.98 & 0.32 & 0.00 & $\begin{array}{l}0.38 \\
(0.20-0.70)\end{array}$ \\
\hline Education & 1.15 & 0.40 & 0.00 & 3.16 \\
\hline Diabetes & 0.69 & 0.26 & 0.01 & $\begin{array}{l}1.99 \\
(1.16-3.42)\end{array}$ \\
\hline
\end{tabular}

\section{DISCUSSION}

Most practical definition of anemia is the one given by the World Health Organization (WHO), hemoglobin concentration less than $13 \mathrm{~g} / \mathrm{dl}$ for men and $12 \mathrm{~g} / \mathrm{dl}$ for women. $^{7}$ Based on this definition, our findings revealed high prevalence of anemia among cardiac patients $(60.3 \%)$, more in female than male $(71.4 \%, 49.7 \%$ respectively). De Maria founds that the combination of heart disease and anemia is present in females and it was associated with 3.5 time's greater risk of mortality than for nursing home resident without these dual co morbidity. ${ }^{8}$ Prior studies have suggested that lower hemoglobin may be a risk factor for CVD outcome, in high-risk patients who already have CVD or have many risk factors for CVD, where Sarnak et al., found in a large study for 14410 patients that $(9 \%)$ of adults (men $5 \%$ and women 13\%) of a normal USA population ages 45-64 years, have anemia. Anemia predisposed patients to a risk of developing CVD and it is a risk factor in cardiovascular survival rate. ${ }^{9}$ Our present study revealed significant increase in the prevalence of anemia by increasing age, $(71.1 \%)$ in-patient older than 70 years and 
$(41.2 \%)$ in patients less than 55 years. However, our study pointed out anemia is not limited to aged people but also targeting younger patients. This findings supports previous reports presented by a recent review of epidemiological studies, explicate that anemia prevalence rate, spreads over a wide range, from (3\% to 61\%) among elderly men and from (3\% to $41 \%$ ) among elderly female. ${ }^{10}$ Also Guralink et al., found a rapid rise in anemia prevalence after the age of 50 years, to a rate greater than $(20 \%)$ in person more than 85 years. ${ }^{11}$ Salive et al., found that getting older was significantly and independently related with both hemoglobin level and anemia. ${ }^{12}$ In a study of northwest Iran 2011 shows the highest rate of anemia age group older than 70 years and patients younger than 40 years. ${ }^{13}$

Also in our study we observed that cardiac patients with anemia were less educated $(64.5 \%)$, hypertensive $(65 \%)$, diabetics (70\%), obese (BMI $30 \mathrm{~kg} / \mathrm{m}^{2}$ and more) and with impaired clearance creatinine $(70 \%)$. Our data came in agreement with a study In Saudi Arabia completed, in the Cardio-Vascular Disease Management Program (CVDMP), showed that $(27 \%)$ of patients were anemic, higher prevalence in females $(33.4 \%)$, (63\%) were 60 years, $(74.7 \%)$ were hypertensive, $(77.4 \%)$ had diabetes and $(28.6 \%)$ had renal disease. The anemia prevalence rate $(27 \%)$ is lower than our reported prevalence where anemia among general population is lower than the Palestinians percentage due to variation in socioeconomic status. $^{14}$

The presence of anemia if extended for a long period may result in ventricular remodeling and cardiac dysfunction. ${ }^{15,16}$ It causes important physiologic effects on the cardiovascular system. Metabolic effect induced by anemia can result in direct myocardial toxicity, myocyte dysfunction, water retention' which could be harmful in patients with heart failure. ${ }^{17-19}$ As we know Anemia is a common co morbidity and predictor of mortality in patients with chronic Heart Failure (HF). In recent years, the prevalence rate of anemia in patients with $\mathrm{HF}$ has received increasing attention; the rate of $\mathrm{HF}$ is $20 \%$ in developed countries. Chronic HF, affects $1-2 \%$ of the European population, is an important cause of mortality and disability. ${ }^{20,21}$ Groenveld et al. found that prevalence of anemia was $37.2 \%$ in a meta-analysis of 34 studies on 150, 180 patients with HF between 2001 and 2007 and concluded that, during management of these patients, it is quite helpful to be aware of the factors that are associated with mortality and morbidity. ${ }^{22}$

Over the past years, clinical surveys and trial, showed that the prevalence rate of anemia in HF patients have resulted in ranges from $9.9 \%$ in Valsatran HF trial (ValHeft), to $(55.6 \%)$ in the study by Silverberg, despite medical therapies, the annual mortality rate was $20 \%$. $^{23,24}$ In addition $30-40 \%$ of patients with HF, die within the first year, and $60-70 \%$ of these patients die within five years following diagnosis. ${ }^{25}$ OPTIME CHF trials showed that every $1 \mathrm{~g} / \mathrm{dl}$ fall in hemoglobin level is independent risk factors for death and readmission. ${ }^{26}$

The presence of anemia with other risk factors including chronic kidney disease, diabetes mellitus is associated with increased mortality, hospitalization and morbidity. ${ }^{27}$ Different studies suggest that anemic patients with CHF are more likely to be older, female with more clinical symptom of HF, higher hospitalization rate, history of diabetes and renal insufficiency. ${ }^{28}$ Our findings is coming in accordance with the data of all these studies, anemia was present in $(74.9 \%)$ of study population with $\mathrm{CHF}$, most of patients were females with high risk of co morbidity.

Considering profile and clinical implications of anemia in-patient with (CAD), several studies believe that presence of anemia has increased ischemic symptoms, and contributes to the occurrence of myocardial ischemia, associated with a worse prognosis. ${ }^{29}$ In hospitals, anemia in patients presenting with Acute Coronary Syndrome (ACS), varies between $(15 \%)$ and $(43 \%))^{30-32}$ The prevalence of anemia in patient presenting with ACS in a study found in Barcelona Spain during the period (2009$2010)$ was $(25 \%)$, and it is a predictor of mortality and cardiovascular complication. ${ }^{33}$

For the explanation of the anemia causes Salisbury et al., suggest that up to $(57.5 \%)$ of patients admitted with normal hemoglobin value acquires anemia during hospital admission. ${ }^{34}$ Patients with so-called nosocomial anemia have higher morbidity and mortality during first year of follow up than those who maintain normal hemoglobin value. ${ }^{35}$ Bleeding in patients with acute coronary syndrome is not negligible and is due to anti platelets and anticoagulants therapy, and may influence the prognosis. Only a small number of authors have suggested that repeated blood sample, and an inflammatory state in ACS has been described as possible causes. $^{36,37}$ In northwest Iran, Azin et al., found that the prevalence of anemia in ischemic heart disease was less than other CVDs (22\%), and the study did not discuss the various ranges of hemoglobin concentration affect the risk of hospitalization and mortality. In our study we found that anemia in CAD was (46.10\%).

There are scarce available data concerning the prevalence of anemia in patient suffering from VHD. Available data concerning the subject has been reported by Fyeza Hassan in case report study of aortic stenosis and gastrointestinal bleeding. ${ }^{38}$ In our analysis, the highest proportion belonged to VHD with prevalence rate of (77.8\%). This could be explained by the use of dual anti platelet or warfarin therapy that increases the risk of gastrointestinal bleeding in cardiac patients.

Additionally, anemia in hypertension is characterized by pro atherosclerotic condition, with impaired endothelial function, which is an independent predictor of mortality. ${ }^{39}$ In our study the percent is $(54 \%)$ probably 
due to uncontrolled hypertension associated with others risk factors mainly diabetes, impaired kidney function and low education level. In a study in Australia about 187 hypertensive patients, the prevalence of anemia was $(16 \%)$ and was higher in patients with uncontrolled hypertension. ${ }^{40}$ Moreover, a study in Iran reported the prevalence of hypertension in anemic patients as $(20.5 \%)$.

\section{CONCLUSION}

In our study, it is clear that prevalence of anemia among cardiac patients is higher than the prevalence among the general population, and the risk is higher among women, poor and less educated people. Clinician should be aware that anemia is common among in-patients with cardiovascular disease and that it is associated risk of morbidity and mortality, and treatment of anemia may be helpful to reduce the risk. The limitations of our study were, less number of patients was included and this is a single center study, CVSDs was diagnosed by noninvasive cardiac investigations and findings may not be generalized to different populations and it requires multicenter.

\section{ACKNOWLEDGEMENTS}

The authors would like to thank research committee of CAIMS, for permission to publish this manuscript.

\section{Abbreviations}

CVSDs: Cardio vascular diseases

NCDs: Non-communicable diseases

TTE: Trans-thoracic-two-dimensional echocardiography

ECG: Electrocardiography

DSE: Dobutamine stress echocardiography

No.: Numbers

Hb: Hemoglobin

CL: Creatinine clearance

Funding: No funding sources

Conflict of interest: None declared

Ethical approval: The study was approved by the institutional ethics committee and invasive cardiac diagnostic investigation study

\section{REFERENCES}

1. Kumar, Abbas, Fausto, Aster. Anemia. In: Kumar, Abbas, Fausto, Aster, eds. Robbins and Cotran's Pathogenic Basis of Disease. 8th ed. India: Elsevier Saunders; 2010: 639.

2. United Nations Relief and Work Agency for Palestine Refugees in the Near East (UNRWA). Annual report of the department of health, 2006. In: UNRWA, eds. UNRWA Report. Jordan: UNRWA; 2006: 5-107.

3. Joyce A, Wahr. Anemia and cardiovascular disease. Transfus Altern Transfus Med. 2008;1(2):24-30.
4. Fauci A, Braunwald E, Kasper D, Hauser S, Longo D, Jameson J, et al. Anemia and Polycythemia. In: John W. Adamson, Dan L. Longo, eds. Harrison's Principles of Internal Medicine. 17 ed. New York: McGraw-Hill; 2008: 458.

5. Sarnak MJ, Tighiouart H, Manjunath G, MacLeod B, Griffith J, Salem D, et al. Anemia as a risk factor for cardiovascular disease in the atherosclerosis risk in communities (ARIC) study. J Am Coll Cardiol. 2002;40(1):27-33.

6. Chaves PH, Semba RD, Leng SX, Woodman RC, Ferrucci L, Guralnik JM, et al. impact of anemia and cardiovascular disease on frailty status of community-dwelling older women: the women's health and aging studies II and I. J Gerontol Series A: Biol Sci Med. 2005;60(6):729-35.

7. Patel KV. Epidemiology of anemia in older adults. Seminars Hematol. 2008;45(4):210-7.

8. De Maria R, Ripamonti V, Sandri R, Ceretti AP, Ferratini $\mathrm{M}$. The negative prognostic synergism of anemia and heart disease in female nursing home residents. Am J Cardiol. 2005;96(10):1460-2.

9. Komajda M. Prevalence of anemia in patients with chronic heart failure and their clinical characteristics. J Cardiac Failure. 2004;10:1-4.

10. Ble A, Fink JC, Woodman RC, Klausner MA, Windham BG, Guralnik TM, et al. Renal function, erythropoietin and anemia of older persons: the Chianti study. Arch Intern Med. 2005;165:2222-7.

11. Guralnik JM, Eisenstaedt RS, Ferrucci L, Klein HG, Woodman RC. Prevalence of anemia in persons 65 years and older in the United States: evidence for a high rate of unexplained anemia. Blood. 2004;104(8):2263-8.

12. Salive ME, Cornoni-Huntley J, Guralnik JM, Phillips CL, Wallace RB, Ostfeld AM, et al. Anemia and hemoglobin levels in older persons: relationship with age, gender, and health status. J Am Geriatr Soc. 1992;40:489-96.

13. Azin Alizadehasl, Zahra Golmohammadi, Lale Panjavi, Siamak Mahmoodmoradi, Rasoul Azarfarin. The incidence of anemia in adult patients with cardiovascular diseases in northwest Iran. Cardiovasc Res Centre. 2011;61(11):1091-5.

14. Raed Odeh, M. B. Bdeir, Tara Conboy. Prevalence of anemia in a Saudi population with chronic heart failure. J Saudi Heart Assoc. 2012;24(4):277-8.

15. Varat MA, Adolph RJ, Fowler NO. Cardiovascular effects of anemia. Am Heart J. 1972;83(3):415-26.

16. Gerry JL, Baird MG, Fortuin NJ. Evaluation of left ventricular function in patients with sickle cell anemia. Am J Med. 1976;60(7):968-72.

17. Riva E, Tettamanti M, Mosconi P, Apolone G, Gandini F, Nobili A, et al. Association of mild anemia with hospitalization and mortality in the elderly: the health and anemia population-based study. Haematologica. 2009;94(1):22-8.

18. Hegde N, Rich MW, Gayomali C. The cardiomyopathy of iron deficiency. Text Heart Inst J. 2006;33(3):340-4. 
19. Anand IS, Chandrashekhar Y, Ferrari R, PooleWilson PA, Harris PC. Pathogenesis of oedema in chronic severe anemia: studies of body water and sodium renal function, hemodynamic variables, and plasma hormones. Br Heart J. 1993;70(4):357-62.

20. Pocock SJ, Wang D, Pfeffer MA, Yusuf S, McMurray JJ, Swedberg KB, et al. Predictors of mortality and morbidity in patients with chronic heart failure. Eur Heart J. 2006;27(1):65-75.

21. Velavan P, Khan NK, Goode K, Rigby AS, Loh PH, Komajda M, et al. Predictors of short term mortality in heart failure-insights from the Euro heart failure survey. Int J Cardiol. 2010;138(1):63-9.

22. Groenveld HF, Januzzi JL, Damman K, van Wijngaarden J, Hillege HL, van Veldhuisen DJ, et al. Anemia and mortality in heart failure patients a systematic review and meta-analysis. J Am Coll Cardiol. 2008;52(10):818-27.

23. Silverberg DS, Wexler D, Iaina A. The importance of anemia and its correction in the management of severe congestive heart failure. Eur J Heart Fail. 2002;4:681-6.

24. Pocock SJ, Wang D, Pfeffer MA, Yusuf S, McMurray JJ, Swedberg KB, et al. Predictors of mortality and morbidity in patients with chronic heart failure. Eur Heart J. 2006;27:65-75.

25. Velavan P, Khan NK, Goode K, Rigby AS, Loh PH, Komajda M, et al. Predictors of short term mortality in heart failure-insights from the Euro heart failure survey. Int J Cardiol. 2010;138:63-9.

26. Salisbury AC, Kosiborod M. Outcomes associated with anemia in patients with heart failure. Heart Fail Clin. 2010;6:359-72.

27. Silverberg DS, Wexler D, Iaina A, Schwartz D. The role of correction of anemia in patients with congestive heart failure: a short review. Eur J Heart Fail. 2008;10(9):819-23.

28. Adams KF, Patterson JH, Oren RM, Mehra MR, O'Connor CM, Pina IL, et al. Prospective assessment of the occurrence of anemia in patients with heart failure: results from the study of anemia in a heart failure population, STAMINA-HFP registry. Am Heart J. 2009;157(5):926-32.

29. daSilveira AD, Ribeiro RA, Rossini AP, Stella SF, Ritta HA, Stein R, et al. Association of anemia with clinical outcomes in stable coronary artery disease. Coron Artery Dis. 2008;19(1):21-6.

30. Bassand JP, Hamm WC, Ardissino D, Boersma E, Budaj A, Ferna'ndez-Aviles F, et al. Guidelines for the diagnosis and treatment of non-ST-segment elevation acute coronary syndromes. Eur Heart J. 2007;28:1598-660.

31. Bassand JP, Hamm WC, Ardissino D, Boersma E, Budaj A, Ferna'ndez-Avile F, et al. Guia de practica clinica para el diagnostico y tratamiento del sindrome coronario agudo sin elevacion del segmento ST. Rev Esp Cardiol. 2004;60:1070-80.

32. Gonzalez-Ferrer JJ, Garcia-Rubira JC, VivasBalcones D, Nunez-Gil I, Carda Barrio R, FuentesFerrer M, et al. Pronostico intrahospitalario de la hemoglobina en pacientes con sindrome coronario agudo. Rev Esp Cardiol. 2008;61:945-52.

33. Oona M, Merce C, Lluis R. In-hospital acquired anemia in acute coronary syndrome. predictors, inhospital prognosis and one-year mortality. Rev Esp Cardiol. 2012;65(8):742-8.

34. Salisbury AC, Amin AP, Reid KJ, Wang TY, Masoudi FA, Chan PS, et al. Hospital acquired anemia and in-hospital mortality in patients with acute myocardial infarction. Am Heart J. 2011;162:300-9.

35. Salisbury AC, Alexander KP, Reid KJ, Masoudi FA, Rathore SS, Wang TY, et al. Incidence, correlates and outcomes of acute, hospital-acquired anemia in Patients with acute myocardial infarction. Circ Cardiovasc Qual Outcomes. 2010;3:337-46.

36. Shaffer C. Diagnostic blood loss in mechanically ventilated patients. Heart Lung. 2007;36:217-22.

37. Thavendiranathan P, Bagai A, Ebidia A, Detsky AS, Choudhry NK. Do blood tests cause anemia in hospitalized patients? The effect of diagnostics phlebotomy on hemoglobin and hematocrit levels. J Gen Intern Med. 2005;20:520-4.

38. Hasan F, O'Brien CS, Sanyal A, Dalton HR. Aortic stenosis and gastrointestinal bleeding. J R Soc Med. 2004;97(2):81-2.

39. Maria M, Alexandros P, Fragiskos P, Evangelos Z, Dimitris A, George K, et al. Systemic blood pressure profile in hypertensive patients with low hemoglobin concentrations. Int $\mathbf{J}$ Cardiol. 2010;142(1):95-6.

40. Paul B, Wilfred NC, Woodman R, Depasquale C. Prevalence and correlates of anemia in essential hypertension. Clin Exp Pharmacol Physiol. 2008;35(12):1461-4.

DOI: 10.5455/2349-3933.ijam20140810

Cite this article as: Jatav RK, Kumbhare MB, Niveditha C. Chronic anemia in adult patients with cardiovascular diseases, diagnosed clinically and by trans-thoracic-2-dimensional echocardiography: a semi-urban tertiary care teaching hospital study. Int J Adv Med 2014;1:89-95. 